\title{
Prenatal Effects of Different Intra-Uterine Milieus on Fetal Glucose Sensing Mechanisms during Gestation in Rats
}

Maher Abd El-Naby Kamel*

Department of Biochemistry, Medical Research Institute, Alexandria University, Egypt

\begin{abstract}
The intra-uterine milieu programs the health of an individual throughout life. This effect has been called fetal origin of adult disease. The altered maternal metabolism is associated with a diabetogenic effect in the adult offspring The pancreatic glucose-stimulated insulin secretion (GSIS) and peripheral response to insulin are central in glucose homeostasis in fetal circulation and the modulation of these processes during the fetal development may have a serious complications long-lasting. This study was aimed to delineate the prenatal (at gestational day 17) effects of different maternal health challenges on the fetal glucose sensing mechanisms including GLUT2, glucokinase, mitochondrial transcription factor A (mTFA), uncoupling protein 2 (UCP2), phospho-insulin receptor (Phosho-IR) and glucose transporter 4 (GLUT4). We used hyperglycemic, obese and malnourished beside normal female rats to establish pregnancy that was terminated at GD 17. The fetal pancreas, liver, muscle and adipose tissues were obtained for determination of the studied parameters. The results indicated up-regulation of GLUT2, glucokinase, mtTFA and UCP2 expression in fetal pancreas and liver of hyperglycemic mothers fetuses while maternal obesity mildly up-regulate expression of GLUT2, glucokinase and UCP2 in fetal pancreas, liver and adipose tissues, while malnutrition causes down-regulation of UCP2 in pancreas, it up-regulates GLUT2 and glucokinase in liver. In muscle and adipose tissues the level of phosho-IR was increased under maternal hyperglycemia and malnutrition while GLUT4 level increased under maternal diabetes only.
\end{abstract}

We can conclude that the fetal adverse environments can prenatally affect the expression of genes that linked to the development of type 2 diabetes including genes controlling glucose sensing and metabolism.

Keywords: Fetal programming; mtTFA; UCP2; GSIS; GLUT4

Abbreviations: ATP: Adenosine Triphosphate; ADP: Adenosine Diphosphate; ETC: Electron Transport Chain; FAD: Flavine Adenine Dinucleotide; GAPDH: Glyceraldehyde-3-phosphate Dehydrogenase; GD: Gestational Day; GLUT: Glucose Transporter; GSIS: GlucoseStimulated Insulin Secretion; HBSS: Hanks' Balanced Salt Solution; IR: Insulin Receptor; IRS: Insulin Receptor Substrates; IUGR: Intrauterine Growth Retardation; mtTFA: Mitochondrial Transcription Factor A; NADH: Nicotinamide Adenine Dinucleotide; PBS: Phosphate Buffered Saline; PND: Postnatal Day; ROS: Reactive Oxygen Species; RT-PCR: Reverse Transcriptase-Polymerase Chain Reaction; UCP: Uncoupling Protein

\section{Background}

The mammalian fetus is completely dependent on the nutrients supplied by its mother. Disturbances in this supply can induce structural and functional changes during fetal development, with long-lasting consequences for growth and metabolism of the offspring throughout life [1]. The intra-uterine milieu, therefore programs to a certain extent the health of an individual throughout life. This effect has been called "fetal origin of adult disease" [2]. The altered maternal/fetal metabolism appears to be associated with a diabetogenic effect in the adult offspring even in the absence of genetic predisposition [3]. This fetal programming of type- 2 diabetes might considerably contribute to the global burden of diabetes [4].

During early developmental stages the metabolic response to nutrient supply is tightly coordinated by nutrient and energy-sensing mechanisms. During theses stages glucose is the essential metabolic substrate and any alterations in its availability, sensing and metabolism can impact fetal development.

The glucose and insulin homeostasis is based on glucose metabolism in $\beta$-cell of pancreas by what is called Glucose-Stimulated
Insulin Secretion (GSIS). The glucose sensing apparatus in $\beta$-cell is composed of low affinity glucose transporter (GLUT2) and low-affinity glucose phosphorylating enzyme glucokinase [5]. The classical scheme of GSIS is depends on the production of ATP molecules by cytoplasmic and mitochondrial metabolism of glucose [6]. The ratio of ATP/ADP increases as processing of the glucose increase, leading to closure of $\mathrm{K}_{\text {ATP }}$ channels causing depolarization of the plasma membrane and opening of $\mathrm{Ca}^{2+}$ channels. The entry of $\mathrm{Ca}^{2+}$ then triggers exocytosis of the insulin granules. However, the precise signals that couple glucose metabolism to insulin secretion are still incompletely understood. Recently, many suggest that reactive oxygen species (ROS) derived from mitochondrial glucose metabolism are potential metabolic signals that facilitate insulin secretion $[7,8]$

In liver the glucose sensing is completely controlled by GLUT2 and glucokinase activity [9] while in muscle and adipose tissues the glucose uptake is controlled by GLUT4 which translocated from intracellular localization into membrane bound form upon activation of insulin receptor (IR) by insulin which cause autophosphorylation of $\beta$-subunit of the receptor to form phospho-IR then activates

*Corresponding author: Maher Abd El-Naby Kamel, Assistant Professor of Biochemistry, Medical Research Institute-Alexandria University, 165 El-Horreya Avenue, El-Hadara, Alexandria, Egypt, Tel: 002-01227151191; Fax: 002-034283719; E-mail: maherrashwan@hotmail.com

Received February 03, 2012; Accepted March 28, 2012; Published March 30 2012

Citation: Kamel MA (2012) Prenatal Effects of Different Intra-Uterine Milieus on Fetal Glucose Sensing Mechanisms during Gestation in Rats. J Diabetes Metab 3:181. doi:10.4172/2155-6156.1000181

Copyright: ( 2012 El-Naby Kamel MA. This is an open-access article distributed under the terms of the Creative Commons Attribution License, which permits unrestricted use, distribution, and reproduction in any medium, provided the original author and source are credited. 
downstream substrates which finally end by translocation of GLUT4 from intracellular into plasma membranes [10].

So, mitochondria is the main player in glucose sensing and metabolism as it play a primary role in cellular energetic metabolism and homeostasis including ion homeostasis, amino acid metabolism, signal transduction and apoptosis [11]. These mitochondrial functions have been shown to play important role during early embryonic development [12]. Mitochondrial biogenesis, dynamics, homeostasis and regulation of oxidative-phosphorylation are regulated by the nuclear encoded genes. One of these genes is mitochondrial transcriptions factor A (mtTFA), a nuclear encoded factor that translocates to mitochondria where it is essential for biogenesis, mitochondrial DNA (mtDNA) expression, replication and maintenance [13]. Uncoupling proteins (UCPs), another nuclear encoded proteins are located in the inner membrane of the mitochondria, they act as a channel which drain protons from mitochondrial intermembrane space directly into the matrix, thereby "uncoupling" electron transport from the production of ATP [14]. UCP2 is the only uncoupling protein present in rodent and human pancreatic beta cells, hepatocytes and white adipose tissues. Studies have implicated UCP2 in the regulation of inhibition of insulin secretion and action through inhibition of ATP production and free fatty acid (FFA) metabolism and control of reactive oxygen species (ROS) formation [14-16]. Recent study has implicated the UCP2 in the pathogenesis of type 2 diabetes mellitus [17].

Many studies have implicated maternal diabetes; overnutrition and malnutrition in the development of diabetes and metabolic syndrome in the offspring $[18,19]$. However, most of these studies focused on the postnatal period however, the prenatal period are very critical. We aimed to delineate the prenatal (at gestational day 17) effects of different maternal health challenges (induced pre-pregnancy) on the fetal parameters of glucose sensing mechanisms including mtTFA, UCP2, insulin receptor and GLUT4.

\section{Experimental Procedures}

\section{Chemicals}

Rat phospho-insulin receptor $\beta$-subunit (Tyr 1162/1163) star ELISA kit was purchased from Millipore (USA) and rat Glucose transporter 4 ELISA Kit was purchased from EIAab (China). Streptozotocin, collagenase, Hanks' Balanced Salt Solution (HBSS), penicillin, streptomycin, Ficoll, RPMI 1640 medium and dithizone were obtained from Sigma-Aldrich Chemie GmbH (Germany). GenJet RNA isolation kit is obtained from Fermentas life science (EU). Onestep RT-PCR kit using RT/PCR Master Mix Gold Beads is obtained from Bioron (Germany). Primers of GLUT2, glucokinase, UCP2 and mtTFA are obtained from Bioneer Co (Bioneer, USA).

\section{Animals}

The animal protocol was approved by the Institutional Animal Care and Use Committee at the Medical Research Institute- Alexandria University. Local Wistar derived strain of rats was used in our study.

Establishment of chronic hyperglycemia: Diabetes was induced in female rat by neonatal injection of streptozotocin $(100 \mathrm{mg} / \mathrm{Kg})$ at postnatal day 5 (PND5) [20]. The chronic hyperglycemia was confirmed in those females after 12 weeks, as fasting blood glucose levels measured by Glucometer (One Touch, Johnson and Johnson Co.) were more than $200 \mathrm{mg} / \mathrm{dl}$. From this induction protocol we obtained viable 78 hyperglycemic females all of which were maintained under normal control diet (Table 1) throughout the experiment.

\begin{tabular}{|c|c|c|c|}
\hline $\begin{array}{l}\text { Macronutrients } \\
\text { (g/kg diet) }\end{array}$ & Control diet & Low-protein diet & Obesogenic diet \\
\hline Protein & 220 & 90 & 300 \\
\hline $\begin{array}{cl}\text { Carbohydrates } \\
\qquad \quad \text { Dextrose } \\
\cdot \quad \text { Corn starch } \\
\cdot \quad \text { Sucrose }\end{array}$ & 631 & 761 & $\begin{array}{l}105 \\
106 \\
140\end{array}$ \\
\hline $\begin{array}{ll}\text { Fat } & \\
& \text { - } \\
& \text { Lard } \\
& \text { corn oil }\end{array}$ & 43 & 43 & $\begin{array}{l}195 \\
70\end{array}$ \\
\hline Cellulose & 54 & 54 & - \\
\hline Vitamin mix & 10 & 10 & 30 \\
\hline Mineral mix & 40 & 40 & 40 \\
\hline $\begin{array}{l}\text { Total energy } \\
\text { (kcal/g diet) }\end{array}$ & 3.8 & 3.8 & 5.4 \\
\hline
\end{tabular}

Table 1: Composition of experimental diets ( $\mathrm{g} / \mathrm{kg}$ diet).

Establishment of obesity: The females were maintained under obesogenic diet (Table 1) for two months after weaning. The female rats that were $20 \%$ heavier than control rats of the same age referred to as obese rat.

Establishment of malnutrition: The females were maintained under low-protein diet (Table 1) for two months after weaning. The female rats that were $20 \%$ lighter than control rat of the same age referred to as malnourished rat. Control healthy female received control diet throughout the experiment

Establishment of pregnancy: After establishing the different conditions pregnancy was induced by mating the females with normal healthy males overnight. Pregnancy was confirmed by the presence of vaginal mucus plug next morning and the pregnancies were proceeded and terminated at gestational day 17 (GD17). During the pregnancy period the animal weights were recorded daily and the cumulative body weight gains were calculated.

Blood glucose levels of all studied females were measured every week during gestation. At gestational day 17 (GD 17) 10 pregnant females were obtained from each group and sacrificed by cervical dislocation. Fetuses with their membranes and placentas were quickly dissected out of the uterine horns. The number of resorbed (dead) fetuses for individual pregnancies was noted and exclude from the study. Each fetuses and its membrane were separated by gentle dissection and rinsed carefully in Phosphate Buffered Saline (PBS). Overall growth and differentiation of the embryos were quantified by direct measurement of crown-rump length. The weights of fetuses and placentas were recorded. Each fetus was dissected to obtain the fetal liver tissues, quadriceps muscles, white adipose tissues and pancreas. From each group of fetuses 10 samples of the fetal tissues and isolated pancreatic islets were obtained and divided into different aliquots and snap-frozen in liquid nitrogen for extractions of RNA using GenJet RNA isolation kit (Fermentas, EU) according to the manufacturer instructions.

Pancreatic islets isolation [21]: For pancreatic islet isolation each fetus was decapitated and the pancreas were removed aseptically and placed in a sterile ice-cold Hanks' Balanced Salt Solution (HBSS). After careful trimming of the pancreas from remnants of gut and spleen, it was chopped into fine $(1 \mathrm{~m})$ pieces and washed twice with HBSS supplemented with penicillin $(100 \mathrm{U} / \mathrm{ml})$, streptomycin $(0.1 \mathrm{mg} / \mathrm{ml})$ and $5 \%$ hepes and transferred to a small sterile vial containing $4 \mathrm{ml}$ collagenase solution $\left(2.5 \mathrm{mg} / \mathrm{ml}\right.$ in $10 \mathrm{mM}$ hepes, $7.5 \mathrm{CaCl}_{2}, 5 \%(\mathrm{v} / \mathrm{v})$ glycerol, $\mathrm{pH} 7.5$ ) and incubated for 40 minutes in a water path at $37^{\circ} \mathrm{C}$. 
Citation: Kamel MA (2012) Prenatal Effects of Different Intra-Uterine Milieus on Fetal Glucose Sensing Mechanisms during Gestation in Rats. J Diabetes Metab 3:181. doi:10.4172/2155-6156.1000181

Page 3 of 7

The digestion was subsequently terminated by adding $10 \mathrm{ml}$ of ice-cold HBSS. Digested tissue was filtered through a 6-cm-diameter cylindrical stainless-steel tea strainer $(0.5 \mathrm{~mm}$ mesh pore size) after washing with ice-cold HBSS, the sample was transferred to $50 \mathrm{ml}$ conical tubes, and centrifuged for $2 \mathrm{~min}$ at $4^{\circ} \mathrm{C}$ at $300 \mathrm{xg}$. The supernatant was discarded and pellet was re-suspended in Ficoll 25\% with $10 \mathrm{mM}$ Hepes, this was layered over by various concentration of Ficoll 23\%, 20.5\% and $11 \%$ to make a density gradient for purification of rat islets. After centrifugation at $300 \mathrm{xg}$ for 15 minutes, the islets were collected from interface between density $11 \%$ and $20.5 \%$. The islets were separated by centrifugation and then washed 3 times with HBSS to remove any Ficoll. Then cells were suspended in RPMI 1640 medium. The purity of the islets were examined by staining with Dithizone and examined microscopically.

\section{RT-PCR analysis}

For semi-quantitative determination of the gene expression of mitochondrial transcription factor A (mtTFA) [22], UCP2 [23], GLUT2 and glucokinase [24] the One-step RT-PCR Master Mix Gold Beads were used. For mtTFA the following primer set were used; forward 5'-GCT TCC AGG AGG CTA AGG AT-3' and reverse 5'-CCC AAT CCC AAT GAC AAC TC-3'. The primer set of UCP2; forward 5'-CAAACAGTTCTACACCAA-3' and reverse 5 '-CGAAGGCAGAAGTGAAGTTGG-3'. The primer set of GLUT2; forward 5'-GAAGAGTGGTTCGGCCCC-3' and reverse 5'TCACACAGTCTCTGATGACCCC-3'. The primer set of glucokinase; forward 5'-CAGATCCTGGCAGAGTTCCAG-3' and reverse $5{ }^{\prime}$-CGGTCCATCTCCTTCTGCAT-3'. To standardize the amount of mRNA in each sample, RT-PCR of Glyceraldehyde-3-phosphate dehydrogenase (GAPDH) was performed in parallel using the following primer set; forward 5'-AATGTGTCCGTCGTGGATCTGA-3' and reverse 5'-GATGCCTGCTTCACCACCTTCT-3'. After the end of the program, the RT-PCR product was run on $1.5 \%$ agarose and stained with ethidium bromide. The bands were visualized by using UV plate. The bands were scanned and the data was analyzed using UVP DOC-ITLS ${ }^{\mathrm{TM}}$ Image \& acquisition and analysis software (Ultra-Violet product, Ltd. Cambridge, UK) that analyze the relative band density to GAPDH band (as internal control).

\section{ELISA measurements}

The fetal tissues homogenates were used for the assessment of phospho-insulin receptor $\beta$-subunit (Tyr 1162/1163) star ELISA kit (Millipore, USA) and GLUT4 by Rat Glucose transporter 4 ELISA Kit (EIAab, China) according to the manufacturer's instructions.

\section{Statistical analysis}

All the data is presented as mean \pm SEM. Statistical analysis was performed using SPSS software for Windows (SPSS, Chicago, IL). Student's $t$ test and ANOVA were used to assess differences. Probability values $(p)<0.05$ were considered to be statistically significant

\section{Results}

\section{Pregnancy outcome at GD17}

The chronic hyperglycemic rats displayed blood glucose level four to five times greater than non-diabetic control group and other groups. In all groups and control mothers the blood glucose concentration was not affected by gestational age (Figure 1).The general effects of the different experimental gestational conditions on the outcome of pregnancy at GD17 are summarized in Table 2, 3. While no gross anatomical malformations could be detected in the embryos of control, obese and malnourished mothers, 5 out of 10 hyperglycemic pregnancies (about 50\%) had malformed embryos. The numbers of implantations per litter were smaller and fetal deaths represented by fetal resorption, were much larger in hyperglycemic, obese and malnourished pregnancies.

Results indicated that, the maternal hyperglycemia and malnutrition were associated with fetal growth retardation (as indicated by lower CRL and fetal weight) and decreased weight gain, while maternal

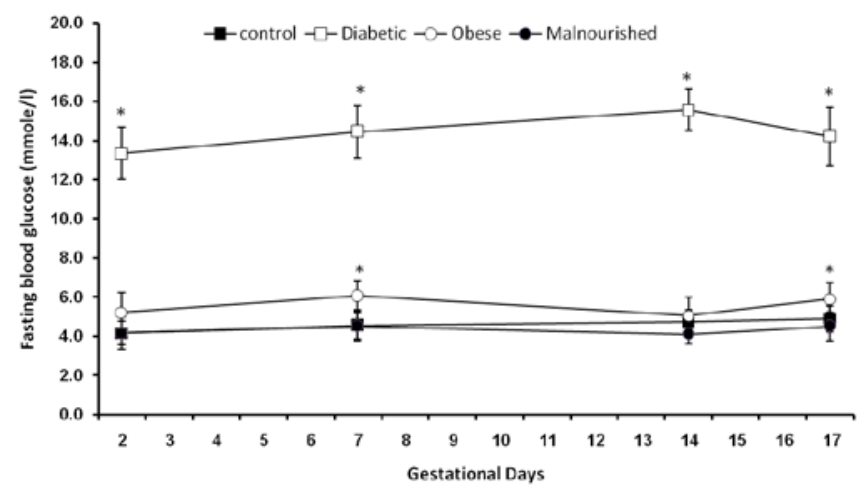

Figure 1: Maternal fasting blood glucose during gestation. Data presented as means \pm SEM, *significant different from control values by ANOVA $(p<0.05)$.C

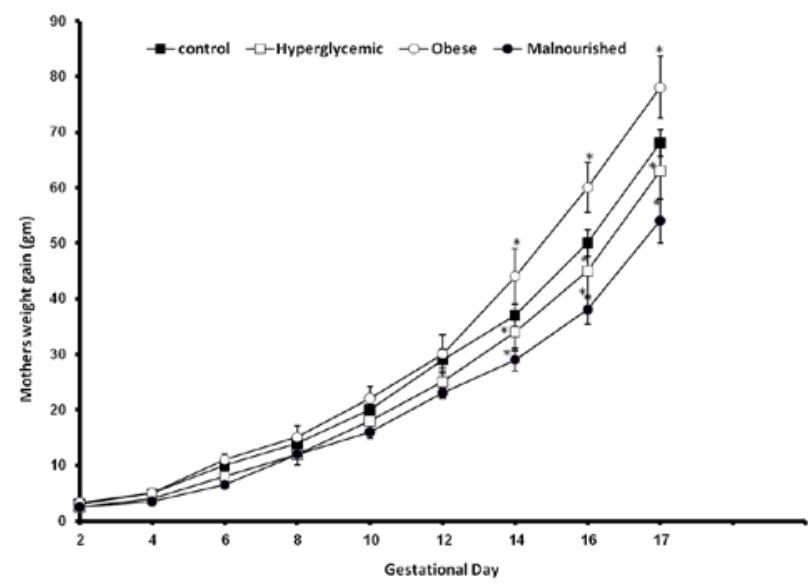

Figure 2: Maternal weight gain during gestation. Data presented as means \pm SEM, *significant different from control values by ANOVA $(p<0.05)$.

\begin{tabular}{|l|l|l|l|l|}
\hline & $\begin{array}{l}\text { Control } \\
\text { mothers }\end{array}$ & $\begin{array}{l}\text { Hyperglycemic } \\
\text { mothers }\end{array}$ & $\begin{array}{l}\text { Obese } \\
\text { mothers }\end{array}$ & $\begin{array}{l}\text { Malnourished } \\
\text { mothers }\end{array}$ \\
\hline No. of litters & 10 & 10 & 10 & 10 \\
\hline $\begin{array}{l}\text { Total No. of } \\
\text { implantation }\end{array}$ & 130 & 91 & 92 & 65 \\
\hline $\begin{array}{l}\text { No. of implantation } \\
\text { per litter }\end{array}$ & 13 & 9 & 9 & 6 \\
\hline No. of viable fetuses & 127 & 74 & 87 & 58 \\
\hline No. of resorption & 2 & 10 & 5 & 7 \\
\hline $\begin{array}{l}\text { No. of litters with } \\
\text { malformed fetuses }\end{array}$ & 0 & 5 & 0 & 0 \\
\hline $\begin{array}{l}\text { No of malformed } \\
\text { fetuses }\end{array}$ & 0 & 7 & 0 & 0 \\
\hline
\end{tabular}

Table 2: Morphologic outcome of the different pregnancies at gestational day 17 


\begin{tabular}{|l|l|l|l|l|}
\hline & $\begin{array}{l}\text { Control } \\
(\mathbf{n}=127)\end{array}$ & $\begin{array}{l}\text { hyperglycemic } \\
(\mathbf{n = 7 4 )}\end{array}$ & $\begin{array}{l}\text { Obese } \\
(\mathbf{n}=87)\end{array}$ & $\begin{array}{l}\text { Malnourished } \\
(\mathbf{n}=58)\end{array}$ \\
\hline Fetal weight (gm) & $2.1 \pm 0.17$ & $1.9 \pm 0.2^{*}$ & $2.06 \pm 0.19$ & $1.8 \pm 0.15^{*}$ \\
\hline CRL (mm) & $20 \pm 2.5$ & $18 \pm 1.5^{*}$ & $20 \pm 2.4$ & $16 \pm 2.4^{*}$ \\
\hline $\begin{array}{l}\text { placental weight } \\
\text { (gm) }\end{array}$ & $0.51 \pm 0.1$ & $0.61 \pm 0.14^{*}$ & $0.53 \pm 0.15$ & $0.49 \pm 0.18$ \\
\hline
\end{tabular}

Data presented as Mean \pm SEM. "significantly different from control value by ANOVA $(p<0.05)$

Table 3: Feta and placental weight and crown-rump length at GD17.

obesity causes fetal overgrowth and increased weight gain compared to control pregnancy (Figure 2 and Table 3 ).

\section{Pancreatic and hepatic GLUT2 and glucokinase gene expression}

The deranged intrauterine milieu used in this study cause a significant change in the expression of GLUT2 and glucokinase in fetal tissues. As shown in Figure 3 and 4 the maternal hyperglycemia causes about 2-fold and 3-fold increase of gene expression of GLUT2 and glucokinase; respectively, in fetal pancreas and liver. Maternal obesity and malnutrition also cause up regulation of GLUT2 and glucokinase expression in fetal pancreas and liver (Figure 3,4). However, obesity produces more prominent effect than malnutrition in fetal pancreas, in the liver the situation was reversed especially in glucokinase expression which shows about 2.7-fold increase with malnutrition (Figure 4).

\section{Tissues UCP2 and mtTFA gene expression}

The results indicated that the applied conditions have effects on the studied parameters in the fetal organs especially with hyperglycemia and malnutrition. The gene expression of mtTFA at mRNA level after normalization to GAPDH gene showed no significant change in all studied tissues except in pancreas of fetuses of hyperglycemic mothers which show an increased level of mtTFA mRNA by about $39 \%$ compared to fetal pancreas of control mother (Figure 5). UCP2 mRNA shows up regulation in the pancreas (20 and 7\%) and liver (16 and 13\%) of fetuses of hyperglycemic and obese mothers, respectively compared to control fetuses. Also, maternal obesity cause up regulation of UCP2 in adipose tissues. Fetal tissues of malnourished mothers showed down regulation of UCP2 mRNA in pancreas and liver (Figure 6).

\section{Muscle and adipose tissues Phospho-IR $\beta$ subunit and GLUT4}

The fetal peripheral tissues skeletal muscle and white adipose tissues showed derangements in the insulin signaling pathway especially in fetuses of hyperglycemic and malnourished mothers. Under hyperglycemic and malnourished gestation the fetal muscles showed increased levels of activated insulin receptor (phospho-IR) by about 37.3 and $33 \%$. Also, adipose tissues showed the same pattern of change; phospho-IR increased by 36.6 and $27 \%$ with maternal hyperglycemia and malnutrition; respectively. Under intrauterine hyperglycemic environment GLUT4 increased by 41 and $50 \%$ in fetal muscles and adipose tissues respectively compared to control tissues (Figure 7, 8). While obesity showed no significant change in the studied parameters (Figure 7,8), the maternal malnutrition during gestation caused a slight but not significant, decrease in the fetal muscle and adipose tissues content of GLUT4 (Figure 8).

\section{Discussion}

The present study was undertaken to evaluate the most relevant type of the adverse intrauterine environments to the fetal reprogramming of glucose sensing by fetal tissues and to determine whether abnormalities

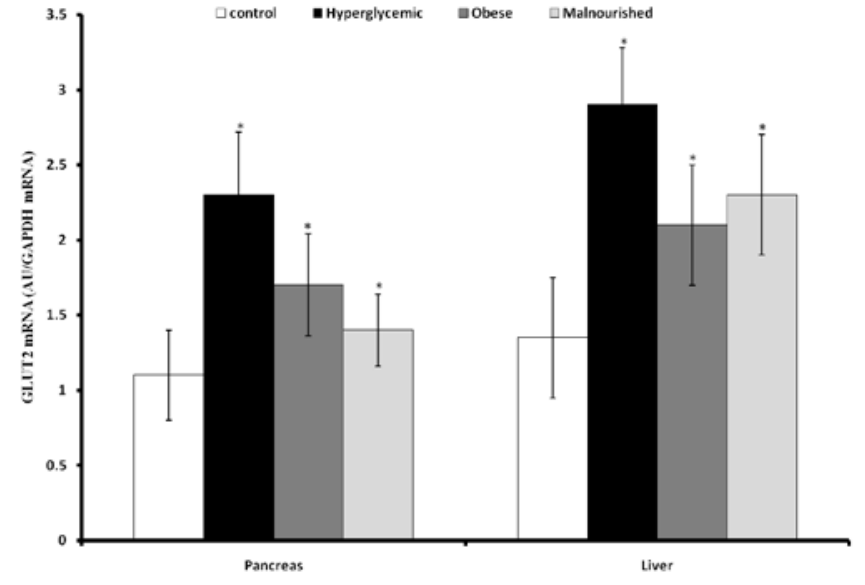

Figure 3: Fetal pancreas and liver GLUT2 mRNA relative expression at GD17 of control, hyperglycemic, obese and malnourished pregnancy. Data presented as means \pm SEM, *significant different from control values by ANOVA $(p<0.05), n=8$.

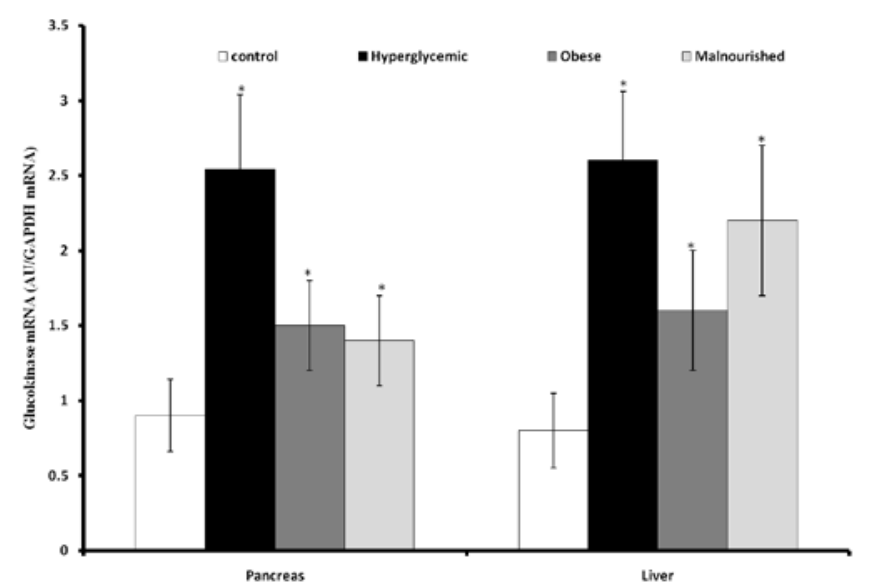

Figure 4: Fetal pancreas and liver glucokinase mRNA relative expression at GD17 of control, hyperglycemic, obese and malnourished pregnancy. Data presented as means \pm SEM, *significant different from control values by ANOVA $(p<0.05), n=8$.

of glucose homeostasis could be a common consequence of prenatal nutritional imbalances and may predispose to glucose intolerance in adult offspring. In the present study the maternal health challenges were induced pre-gestational just after weaning. Most studies dealing with the fetal programming induce the maternal insult during late (last week) or mid ( $2^{\text {nd }}$ week) gestation $[18,19,25]$. But such designs for studies into the effect of nutrient restriction are complicated by the fact that short-term deficiencies are buffered to varying degrees by intracellular reserves of nutrient. Also, pre-gestational challenges are important to cover the pre-implantation period which may be particularly sensitive. Also, our model resembles to large extent the human situation.

In our study we evaluate the effects of the different maternal health status during gestation on the glucose sensing mechanisms in the fetal tissues to clarify the common mechanism by which these conditions program the offspring for adult diabetes.

GLUT2 is involved in metabolic glucose sensing by mediating 


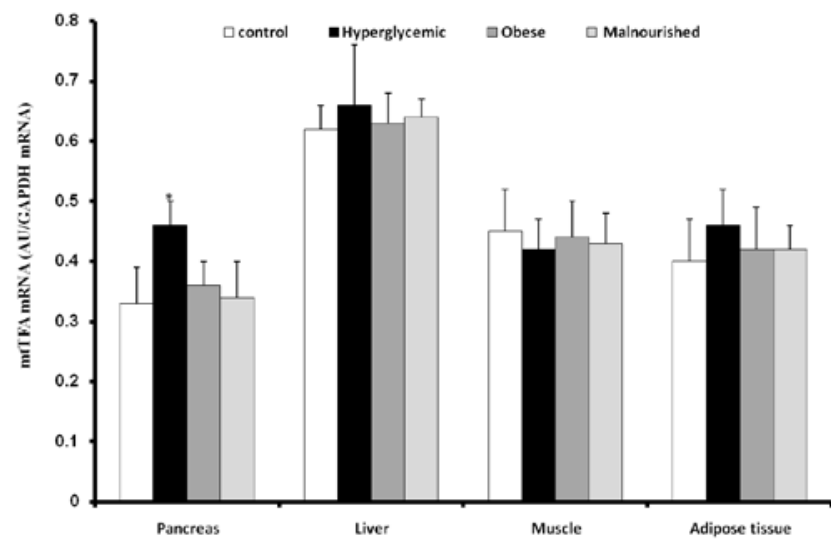

Figure 5: Fetal pancreas, liver, muscle and adipose tissue mtTFA mRNA relative expression at GD17 of control, hyperglycemic, obese and malnourished pregnancy. Data presented as means \pm SEM, *significant different from control values by ANOVA $(p<0.05), n=8$.

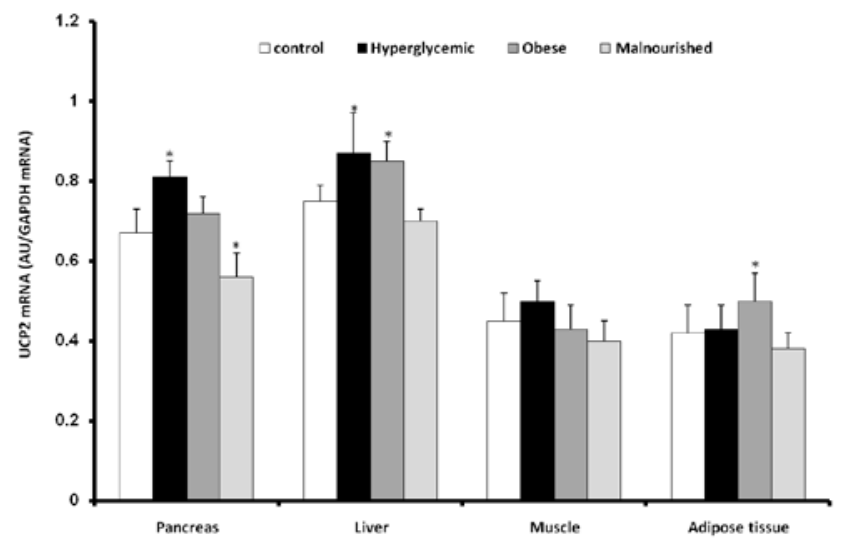

Figure 6: Fetal pancreas, liver, muscle and adipose tissues UCP2 mRNA relative expression at GD17 of control, hyperglycemic, obese and malnourished pregnancy. Data presented as means \pm SEM, *significant different from control values by ANOVA $(p<0.05), n=8$.

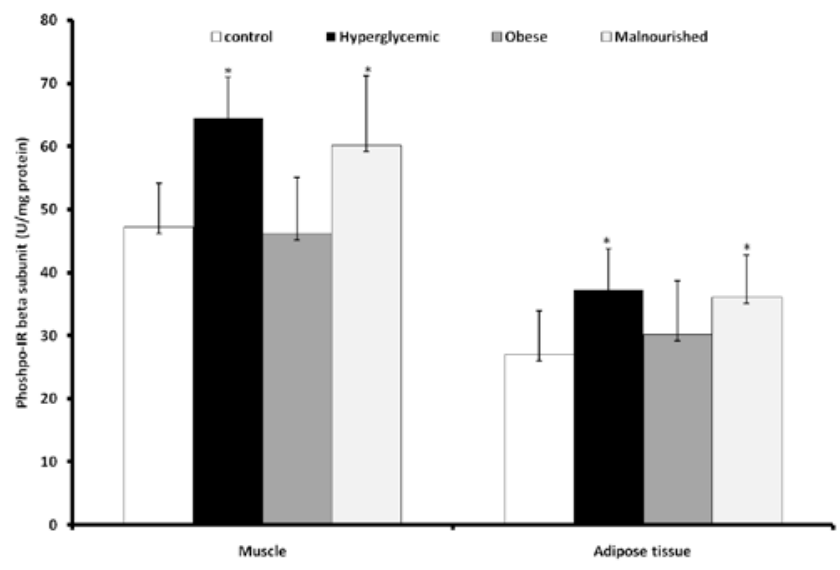

Figure 7: Fetal muscle and adipose tissues content of phospho-IR beta subunit at GD17 of control, hyperglycemic, obese and malnourished pregnancy. Data presented as means $\pm \mathrm{SD}$, *significant different from control values by ANOVA $(p<0.05), n=8$.

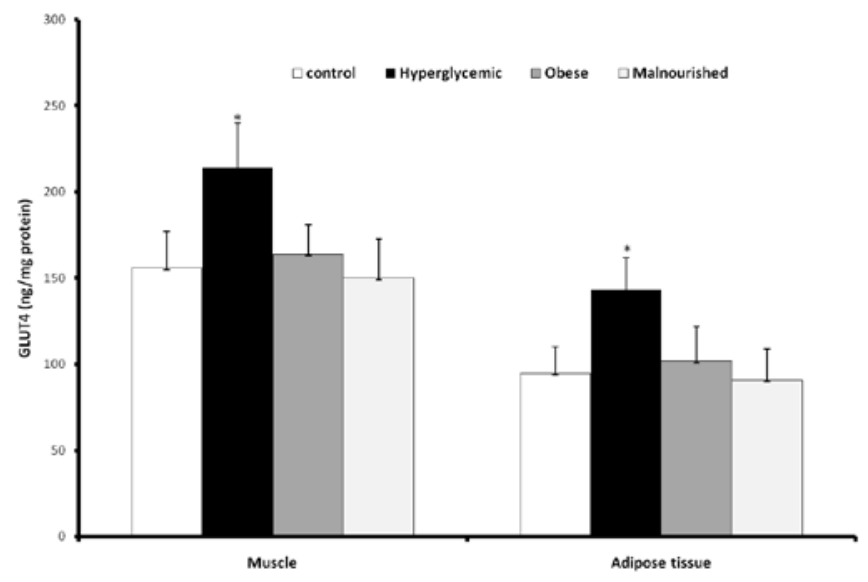

Figure 8: Fetal muscle and adipose tissues content of GLUT4 at GD17 of control, hyperglycemic, obese and malnourished pregnancy. Data presented as means \pm SEM, *significant different from control values by ANOVA $(p<0.05), n=8$.

bidirectional glucose transport, adjusting intracellular glucose concentration, control of food intake and secretion of insulin [26]. GLUT2 gene expression was duplicated in fetal pancreas and liver of maternal hyperglycemia which consistent with the induction effect of glucose on GLUT2 gene expression [27]. Maternal obesity and malnutrition induce milder effect than hyperglycemia on fetal pancreas and liver expression of GLUT2. Glucokinase is a known mediator of glucose sensing in pancreas and liver, maternal diabetes induce its gene expression three fold in fetal pancreas and liver these induction could be mediated by maternal hyperglycemia as glucose has been reported to be a physiological regulator of glucokinase in pancreatic B-cells, while liver glucokinase is controlled by insulin [28]. This differential regulation of glucokinase may interpret the results of induced glucokinase expression in fetal liver ( 2.7 fold) of malnourished pregnancy as low UCP2 in fetal pancreas may induce fetal insulin secretion which may up regulate the glucokinase gene expression as an adaptive response to low amino acids.

Mitochondria play a pivotal role in glucose sensing and metabolism. The mitochondria of rat embryo undergo considerable changes throughout organogenic period [29]. In the current work we measured the gene expression of mtTFA; a key nuclear gene involved in mitochondrial replication, transcription and function, in order to understand the fetal mitochondrial biogenesis under metabolically imbalanced intrauterine conditions. The results indicated that the mtTFA gene expression is enhanced in fetal tissues under hyperglycemic condition especially in pancreas and adipose tissues, while maternal obesity and malnutrition show no effect on mtTFA gene expression. The increased expression of mtTFA could induce mitochondrial biogenesis and function to meet the high metabolic need due to diffusion of glucose into the developing fetus as a result of maternal hyperglycemia which activates the fetal pancreatic cells to secret insulin by GSIS. This notion should be confirmed by another study to evaluate the number of mitochondria and mitochondrial DNA copy number during this critical period of development. Fetal hyperinsulinemia was documented in human fetus of diabetic mother which may cause macrosomia [30].

The increased expression of UCP2 in fetal pancreas of chronic hyperglycemic mothers may represent feed-back mechanism to inhibit the increase of insulin secretion. Its up-regulation is associated 
with decreased ATP production, closure of ATP-sensitive potassium channels, decreased mitochondrial ROS and impairment of GSIS [31]. An inverse relationship between suppression of GSIS and UCP-2 expression has been demonstrated by In vitro studies [32]. Moreover, rat clonal beta cell line (INS-1E) genetically modified to overexpress UCP2 gene showed increased survival after treatment with the $\mathrm{H}_{2} \mathrm{O}_{2}$ [33]. Likewise, beta cells exposed to oxidative stress attempted to overcome the toxicity of $\mathrm{H}_{2} \mathrm{O}_{2}$ by the induction of UCP2 mRNA [34]. Also it was demonstrated that endothelial cells from retinal cells incubated with high glucose levels up-regulate UCP2 expression for protection from ROS damage derived from glucotoxicity [35]. On the other hand, UCP-2 deficient mice had increased ATP production and GSIS [36].

Up regulation of UCP2 was also observed in fetal pancreas, liver and adipose tissues of the offspring of obese mothers. The increased lipids and fatty acid load during gestation of maternal obesity results in high metabolic rate which may be associated with increased ROS generation so the increased UCP2 gene expression may be a protective mechanism to decrease metabolic efficiency through enhancing betaoxidation of extra fatty acids and lipids without the production of ATP and accompanying ROS [17]. It was documented that fatty acids are endogenous physiological regulators associated with increased UCP2 and UCP3 expression in a tissue-specific manner [37]. Also, cell lines derived from heart, liver and pancreatic islets respond to the addition of different fatty acids to the culture medium with an increase in UCP2 mRNA levels [37,38]. It was documented that $\beta$-cell dysfunction can be produced by prolonged exposure to elevated levels of glucose (glucotoxicity) and lipid (lipotoxicity). The mechanisms by which glucolipotoxicity trigger beta cell dysfunction is not completely understood, however ROS production was suggested to play an important role in these mechanisms [39]. The antioxidant effect of UCP2 is of special importance in beta cells as it has low expression and activity of many of the enzymes involved in antioxidant defense [33]. However, increased UCP2 production leads to decreased insulin secretion, predisposing subjects to type 2 diabetes $[31,38,39]$.

The maternal hyperglycemia and obesity up-regulation of UCP2 in fetal pancreas could program the fetal mitochondria for the impaired GSIS postnatal and predispose offspring to glucose intolerance and type-2 diabetes. On the other hand maternal malnutrition causes downregulation of UCP2 especially in fetal pancreas and liver. The poor fetal metabolic environment due to malnutrition necessitates high degree of metabolic efficiency which was accomplished by increased expression of UCP2. This result may interpret the documented enhanced GSIS in early postnatal live of the progeny of malnourished mother [40]. However, the lower expression of UCP-2 observed may participate in the higher ROS production and long-lasting impairment of $\beta$-cell function in the offspring [41]. However, the study of glucose uptake and GSIS in isolated $\beta$-cell is of great importance for further understand of the programming of fetal pancreas for adult glucose intolerance and type 2 diabetes by theses maternal health challenges.

In peripheral tissues the glucose sensing mediated mainly through insulin action on its receptor (IR) and subsequent autophosphorylation by tyrosine kinase inherent activity of the receptor itself then activation of downstream insulin receptor substrates (IRS) that activate certain intracellular pathway that ended by GULT4 translocation. Also, ROS generated by NADPH oxidase (Nox) enzyme are participated in the peripheral insulin action as a second messenger of insulin [42]. GLUT4 is the major insulin-responsive isoform expressed in insulinsensitive tissues such as skeletal muscle, adipose tissue and cardiac muscle [43]. Mammalian embryo has unique metabolic needs that must be met to ensure successful pregnancy and healthy offspring. The family of facilitative glucose transporters (GLUTs) plays a major role in providing metabolic substrates to fetal tissues [44]. Alterations in glucose transport and metabolism at the early stages of development can impact fetal development. Fetal muscle and adipose tissues have elevated content of active IR (phospho-IR) and GLUT4 in fetuses of diabetic and malnourished mothers which may be as a result of increased glucose and then insulin secretion or requirement for de novo synthesis of amino acids and protein, respectively. The fetal peripheral tissues of obese pregnancy show no significant changes in insulin signaling compared to normal fetuses. The kinetics of peripheral glucose uptake and translocation of GLUT4 to the plasma membranes in fetal peripheral tissues are of great importance to understand glucose homeostasis in fetal circulation

Many studies suggested that maternal nutritional states could affect the gene expression of fetuses through epigenetic mechanisms [45]. Several studies suggest that uteroplacental insufficiency, the most common cause of intrauterine growth retardation (IUGR) in the developed world, induces epigenetic modifications in offspring $[46,47]$. In line with these studies our results indicated the different intra-uterine environments appear to be differentially affecting the expression of genes involved in glucose sensing in fetal pancreas and peripheral tissues. So how these different maternal health conditions with different effects produce the same diabetogenic tendency in the offspring? The answer of this question requires further investigations and follows up studies to correlate these different fetal effects to adulthood outcomes.

The pancreatic GSIS and peripheral response to insulin represent the central players in glucose homeostasis in fetal circulation and the modulation of these processes during the fetal development may have a serious complications long-lasting. All of the above clearly indicate that the fetal adverse environments can induce epigenetic alterations prenatally affecting the expression of genes that could be linked to the development of type 2 diabetes including genes critical for mitochondrial development and function and peripheral glucose sensing and metabolism.

\section{Acknowledgements}

This study is a part of project entitled "Intra-Uterine programming of adult diabetes: an experimental study" supported by STDF (Science and Technology Development Fund)-Egypt.

\section{References}

1. Reusens $B$, Remacle C (2006) Programming of the endocrine pancreas by the early nutritional environment. Int J Biochem Cell Biol 38: 913-922.

2. Sinclair KD, Lea RG, Rees WD, Young LE (2007) The developmental origins of health and disease: current theories and epigenetic mechanisms. Soc Reprod Fertil Suppl 64: 425-443.

3. Artes L, Van Assche FA (2006) Animal evidence for the transgenerationa development of diabetes mellitus. Int J Biochem Cell Biol 38: 894-903.

4. Pettitt DJ (1996) Diabetes in subsequent generations. In Diabetes and Pregnancy. An International Approach to Diagnosis and Management Dornhorst A \& Hadden DR (Ed.), Chichester: John Wiley \& Sons: 367-376.

5. Matschinsky FM, Glaser B, Magnuson MA (1998) Pancreatic beta-cell glucokinase: closing the gap between theoretical concepts and experimental realities. Diabetes 47: 307-315.

6. Jensen MV, Joseph JW, Ronnebaum SM, Burgess SC, Sherry AD, et al. (2008) Metabolic cycling in control of glucose-stimulated insulin secretion. Am J Physiol Endocrinol Metab 295: E1287-E1297.

7. Pi J, Zhang Q, Fu J, Woods CG, Hou Y, et al. (2010) ROS signaling, oxidative stress and Nrf2 in pancreatic beta-cell function. Toxicol Appl Pharmacol 244 $77-83$ 
Citation: Kamel MA (2012) Prenatal Effects of Different Intra-Uterine Milieus on Fetal Glucose Sensing Mechanisms during Gestation in Rats. J Diabetes Metab 3:181. doi:10.4172/2155-6156.1000181

8. Leloup C, Tourrel-Cuzin C, Magnan C, Karaca M, Castel J, et al. (2009) Mitochondrial reactive oxygen species are obligatory signals for glucose induced insulin secretion. Diabetes 58: 673-681.

9. Burcelin R, Dolci W, Thorens B (2000) Glucose sensing by the hepatoportal sensor is GLUT2-dependent: in vivo analysis in GLUT2-null mice. Diabetes 49: $1643-1648$

10. Rea S, James DE (1997) Moving GLUT4: the biogenesis and trafficking of GLUT4 storage vesicles. Diabetes 46: 1667-1677.

11. Dimauro S (2004) Mitochondrial medicine. Biochim Biophys Acta 1659: 107 114

12. Thundathil J, Filion F, Smith LC (2005) Molecular control of mitochondrial function in preimplantation mouse embryos. Mol Reprod Dev 71: 405-413.

13. Ekstrand MI, Falkenberg M, Rantanen A, Park CB, Gaspari M, et al. (2004) Mitochondrial transcription factor A regulates mtDNA copy number in mammals. Hum Mol Genet 13: 935-944.

14. Sluse FE, Jarmuszkiewicz W, Navet R, Douette P, Mathy G, et al. (2006) Mitochondrial UCPs: new insights into regulation and impact. Biochim Biophys Acta 1757: 480-485.

15. Shang Y, Liu Y, Du L, Wang Y, Cheng X, et al. (2009) Targeted expression of uncoupling protein 2 to mouse liver increases the susceptibility to lipopolysaccharide/galactosamine-induced acute liver injury. Hepatology 50: 1204-1216.

16. De Souza C, Araujo E, Stoppiglia L, Pauli J, Ropelle E, et al. (2007) Inhibition of UCP2 expression reverses diet-induced diabetes mellitus by effects on both insulin secretion and action. FASEB J 21: 1153-1163.

17. Souza BM, Assmann TS, Kliemann LM, Gross JL, Canani LH, et al. (2011) The role of uncoupling protein 2 (UCP2) on the development of type 2 diabetes mellitus and its chronic complications. Arq Bras Endocrinol Metabol 55: 239248.

18. Smith $\mathrm{NH}$, Ozanne SE (2006) Intrauterine origins of metabolic disease. Reviews in Gynaecological and Perinatal 6: 211-217.

19. Poston L (2010) Developmental programming and diabetes-The human experience and insight from animal models. Best Pract Res Clin Endocrinol Metab 24: 541-552.

20. Arulmozhi DK, Veeranjaneulu A, Bodhankar SL (2004) Neonatal streptozotocininduced rat model of type 2 diabetes mellitus: A glance. Indian J Pharamacol 36: 217-221

21. Amoli MM, Moosavizadeh R, Larijani B (2005) Optimizing conditions for rat pancreatic islets isolation. Cytotechnology 48: 75-78

22. Piantadosi CA, Suliman HB (2006) Mitochondrial transcription factor A induction by redox activation of nuclear respiratory factor 1. J Biol Chem 281: 324-333.

23. Berraondo B, Marti A, Duncan JS, Trayhurn P, Martinez JA (2000) Upregulation of muscle UCP2 gene expression by a new beta3-adrenoceptor agonist, trecadrine, in obese (cafeteria) rodents, but down regulation in lean animals. Int J Obes Relat Metab Disord 24: 156-163.

24. Parton LE, Diraison F, Neill SE, Ghosh SK, Rubino MA, et al. (2004) Impact of PPARgamma overexpression and activation on pancreatic islet gene expression profile analyzed with oligonucleotide microarrays. Am J Physiol Endocrinol Metab 287: E390-E404.

25. Sinclair KD, Singh R (2007) Modeling the developmental origins of health and disease in the early embryo. Theriogenology 67: 43-53.

26. Wood IS, Trayhurn P (2003) Glucose transporters (GLUT and SGLT): expanded families of sugar transport proteins. Br J Nutr 89: 3-9.

27. Im SS, Kang SY, Kim SY, Kim HI, Kim JW, et al. (2005) Glucose- stimulated upregulation of GLUT2 gene is mediated by sterol response element-binding protein-1c in the hepatocytes. Diabetes 54: 1684-1691.

28. Tiedge M, Lenzen S (1995) Effects of glucose refeeding and glibenclamide treatment on glucokinase and GLUT2 gene expression in pancreatic B-cells and liver from rats. Biochem J 308: 139-144.

29. Shepard TH, Muffley LA, Smith LT (1998) Ultrastructural study of mitochondria and their cristae in embryonic rats and primate (N. nemistrina). Anat Rec 252: 383-392.

30. Desoye G, Korgun ET, Ghaffari-Tabrizi N, Hahn T (2002) Is fetal macrosomia in adequately controlled diabetic women the result of a placental defect? -a hypothesis. J Matern Fetal Neonatal Med 11: 258-261.
31. Affourtit C, Brand MD (2008) On the role of uncoupling protein-2 in pancreatic beta cells. Biochim Biophys Acta 1777: 973-979.

32. Pi J, Bai Y, Daniel KW, Liu D, Lyght O, et al. (2009) Persistent oxidative stress due to absence of uncoupling protein 2 associated with impaired pancreatic beta cell function. Endocrinology 150: 3040-3048.

33. Li LX, Skorpen F, Egeberg K, Jфrgensen IH, Grill V (2001) Uncoupling protein-2 participates in cellular defense against oxidative stress in clonal beta-cells. Biochem Biophys Res Commun 282: 273-277.

34. Esteves T, Brand MD (2005) The reactions catalysed by the mitochondria uncoupling proteins UCP2 and UCP3. Biochim Biophys Acta 1709: 35-44.

35. Cui Y, Xu X, Bi H, Zhu Q, Wu J, et al. (2006) Expression modification of uncoupling proteins and MnSOD in retinal endothelial cells and pericytes induced by high glucose: the role of reactive oxygen species in diabetic retinopathy. Exp Eye Res 83: 807-816.

36. Zhang CY, Baffy G, Perret P, Krauss S, Peroni O, et al. (2001) Uncoupling protein-2 negatively regulates insulin secretion and is a major link between obesity, beta cell dysfunction, and type 2 diabetes. Cell 105: 745-755.

37. Thompson MP, Kim D (2004) Links between fatty acids and expression of UCP2 and UCP3 mRNAs. FEBS Lett 568: 4-9.

38. Azzu V, Brand MD (2010) The on-off switches of the mitochondrial uncoupling proteins. Trends Biochem Sci 35: 298-307.

39. Fisler JS, Warden $\mathrm{CH}$ (2006) Uncoupling proteins, dietary fat and the metabolic syndrome. Nutr Metab (Lond) 3: 38

40. Shepherd PR, Crowther NJ, Desai M, Hales CN, Ozanne SE (1997) Altered adipocyte properties in the offspring of protein malnourished rats. $\mathrm{Br} \mathrm{J}$ Nutr 78: $121-129$.

41. Theys N, Ahn M-T, Bouckenooghe T, Reusens B, Remacle C (2011) Materna malnutrition programs pancreatic islet mitochondrial dysfunction in the adult offspring. J Nutr Biochem 22: 985-994.

42. Goldstein BJ, Mahadev K, Wu X (2005) Redox Paradox Insulin Action Is Facilitated by Insulin-Stimulated Reactive Oxygen Species With Multiple Potential Signaling Targets. Diabetes 54: 311-321.

43. Karnieli E, Armoni M (2008) Transcriptional regulation of the insulin-responsive glucose transporter GLUT4 gene: from physiology to pathology. Am J Physio Endocrinol Metab 295: E38-E45.

44. Tonacka T, Ramina N, Garimellab S, Rao R, Seshagirib PB, et al. (2009) Expression of glucose transporter isoforms and the insulin receptor during hamster preimplantation embryo development. Ann Anat 191: 485-495.

45. Pinney E, Simmons RA (2010) Epigenetic mechanisms in the development of type 2 diabetes. Trend Endocrinol Metab 21: 223-229.

46. Park JH, Stoffers DA, Nicholls RD, Simmons RA (2008) Development of type 2 diabetes following intrauterine growth retardation in rats is associated with progressive epigenetic silencing of Pdx1. J Clin Invest 118: 2316-2324.

47. Raychaudhuri N, Raychaudhuri S, Thamotharan M, Devaskar SU (2008) Histone code modifications repress glucose transporter 4 expression in the intrauterine growth-restricted offspring. J Biol Chem 283: 13611-13626. 